\title{
CASE STUDY OF BURA OF 1ST AND 3RD FEBRUARY 2007
}

\author{
Martina Tudor ${ }^{1}$ \\ ${ }^{1}$ Croatian Meteorological and Hydrological Service, Zagreb, Croatia \\ E-mail: tudor@cirus.dhz.hr
}

\begin{abstract}
Two cases when the operational forecast seriously underestimated the wind speed maxima are analysed. The first one in the night between 1st and 2nd February 2007 and the second one in the evening of 3rd February 2007.
\end{abstract}

Keywords: bura,

\section{INTRODUCTION}

The operational forecast is performed using hydrostatic Aladin model with $8 \mathrm{~km}$ horizontal resolution on 37 vertical levels using digital filter initialization (DFI, no data assimilation), semi-Lagrangian horizontal diffusion (SLHD) and prognostic TKE scheme. That forecast is operationally further dynamically downscaled to $2 \mathrm{~km}$ horizontal resolution using the procedure described in Ivatek-Šahdan and Tudor (2004).

\section{DATA AND METHODS}

\subsection{General situation}

On 1st February 2007, the NW jet-stream moved SW across Croatia. Its edge reached the eastern Adriatic coastline around 12 UTC. Then the direction of the jet stream changes, from NW to NE as the jet strengthens and moves SE along the coast. On 3rd February, at 9 UTC another NW jet-stream reaches Croatia, strengthens and changes the wind direction from NW to NE as it reaches further SE by the evening of the same day. The high level wind is first perpendicular to the Dinaric Alps, but later in the $2^{\text {nd }}$ episode it is parallel to the mountains on eastern Adriatic coast.

\subsection{Observed weather}
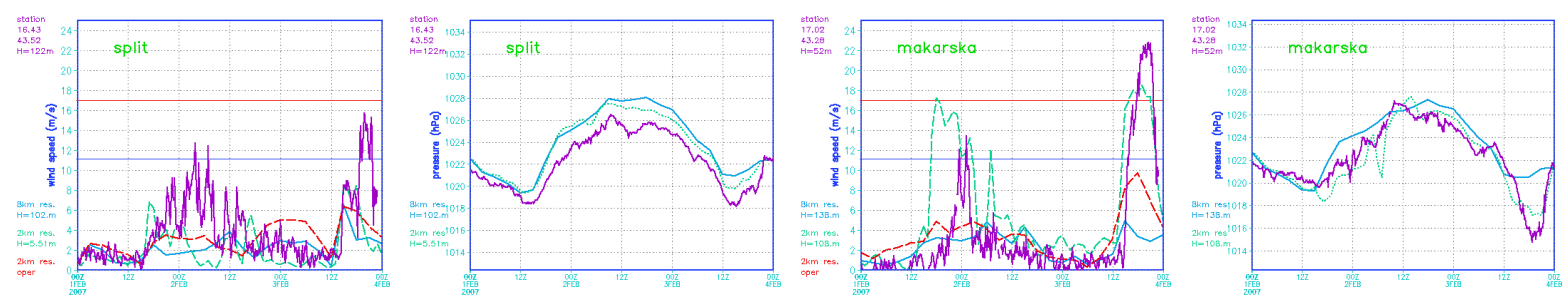

Figure 1. Forecast in $8 \mathrm{~km}$ resolution (blue line), $2 \mathrm{~km}$ dynamical adaptation (red dashed) and $2 \mathrm{~km}$ resolution full run (green dashed) and 10 minute measurements (purple) of $10 \mathrm{~m}$ wind and pressure reduced to mean sea level for Split (left) and Makarska (right) locations. The longitude and latitude of the measuring station locations as well as height are also shown.

During the evening and night on $1^{\text {st }}$ and $2^{\text {nd }}$ February 2007 , measured $10 \mathrm{~m}$ wind speed significantly exceeded the forecast one (Figure 1). Average 10 minute wind speed significantly changed from one interval to the next one. Vertical sounding data (Figure 2) show two temperature inversions, at 850 and at $700 \mathrm{hPa}$, but the upper one is barely noticeable in the Zadar sounding. The second bura episode, in the evening of $3^{\text {rd }}$ February 2007 was characterized by much stronger and more steady $10 \mathrm{~m}$ wind. There were also two temperature inversion layers, one at 900 and $700 \mathrm{hPa}$.

a)

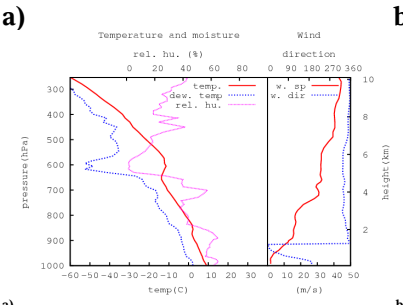

b)

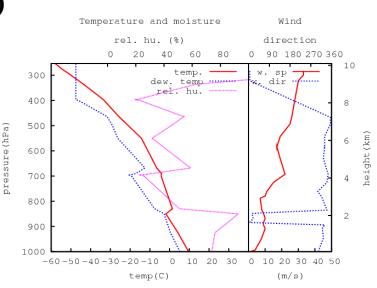

c)

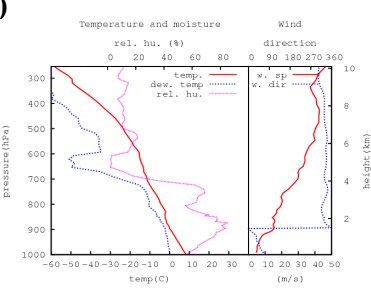

d)

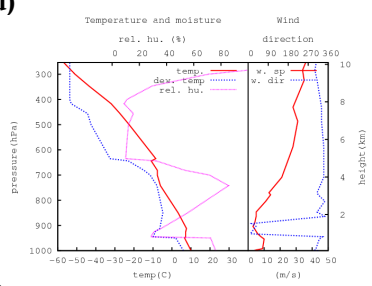

Figure 2. Measured vertical profiles of temperature and wind for Zagreb (a and c) and Zadar (b and d) locations for 12 UTC on $1^{\text {st }}(\mathrm{a}$ and $\mathrm{b})$ and $3^{\text {rd }}$ (c and d) February 2007. 

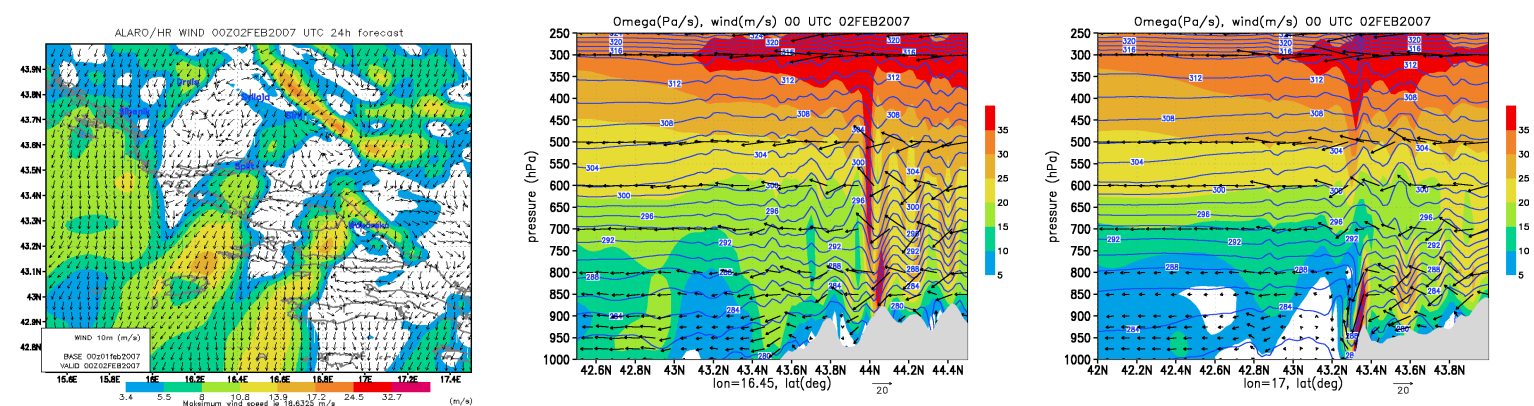

Figure 3. Forecast of wind $10 \mathrm{~m}$ above ground (left) and meridional vertical cross-sections through Split (center) and Makarska (right) for 00 UTC $2^{\text {nd }}$ February 2007. Vertical cross-sections show potential temperature in blue lines and arrows show the direction of vertical velocity component.
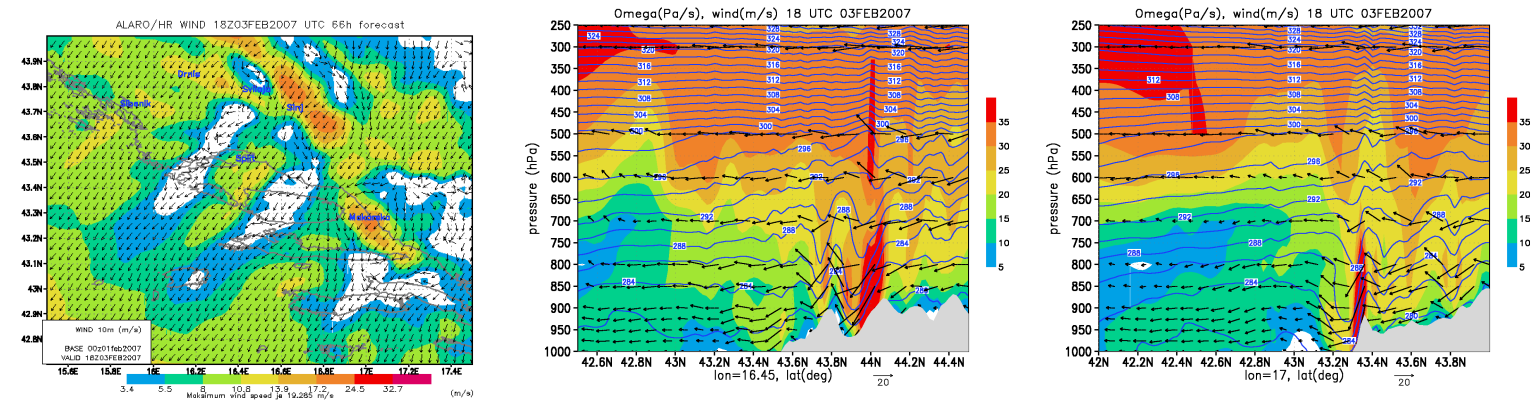

Figure 4. As Figure 3 for 18 UTC $3^{\text {rd }}$ February 2007.

\section{MODEL SETUP}

The full $2 \mathrm{~km}$ resolution forecast alone instead of the operational dynamical adaptation did not improve the forecast, but the full forecast run was used to test the impact of other processes in the model. The possibility that the digital filter initialization (DFI) removed part of the energy of the high-frequency waves from the initial conditions was explored, but the run without DFI did not improve the simulated wind field. There are two horizontal diffusion schemes used simultaneously in the operational model. One is the "standard" $4^{\text {th }}$ order numerical diffusion (ND), and the other is the semi-lagrangian horizontal diffusion (SLHD) scheme. When the intensity of the ND was reduced by a factor of 100, high amplitude waves developed which were responsible for development of the windstorm. Unfortunately not on all locations that were hit by this bura episode.

The first bura episode is characterized by a stable layer above mountains below $700 \mathrm{hPa}$ and less stable layer above (Figure 3) while in the second one the layer up to $500 \mathrm{hPa}$ was far less stable than the one above (Figure 4). In both cases, the high amplitude wave developed on the lee side of Biokovo mountain (right panel of Figures 3 and 4) as well as Dinara mountain upstream of Split (center panel of Figures 3 and 4) but the windstorm is too weak in the Split area (for lat=43.5 in the center panel of Figures 3 and 4).

\section{CONCLUSIONS}

Usage of non-hydrostatic $(\mathrm{NH})$ dynamics did not improve the $10 \mathrm{~m}$ wind forecast but it had a positive impact higher in the atmosphere, where usage of SLHD and NH dynamics reduces the TKE as well as values of extreme PV suggesting that removal of those two mechanisms forces other, like vertical turbulent diffusion, to compensate.

Acknowledgements: The author wishes to thank Ivana Stiperski for advice, literature and for being the patient listener.

\section{REFERENCES}

Ivatek-Šahdan, S. and M. Tudor, 2004: Use of High-Resolution Dynamical Adaptation in Operational Suite and Research Impact Studies. Meteorologische Zeitschrift, 13, No. 2, 1-10 